\title{
Metastatik Kolorektal Kanserli Hastaların RAS Mutasyon Durumuna Göre Klinik ve Patolojik Özellikleri
}

\author{
Mehmet SEZEN ${ }^{1}$, Murat ARAZ ${ }^{2}$
}

1 Afyon Sağlık Bilimleri Üniversitesi Tıp Fakültesi, İç Hastalıkları Anabilim Dalı, Afyon.

2 Necmettin Erbakan Üniversitesi Meram Tıp Fakültesi, İç Hastalıkları Anabilim Dalı, Tıbbi Onkoloji Bilim Dalı, Konya.

\section{ÖZET}

Bu çalışmada metastatik kolorektal kanserli hastalarda tanı anındaki histopatolojik ve klinik özelliklerin RAS mutasyon durumuna göre karşılaştırılması amaçlandı. Bu kesitsel çalıșma için, 01.04.2012-24.08.2017 tarihleri arasında bir üniversite hastanesinin onkoloji merkezinde takip ve tedavisi yapılmış toplam 530 kolorektal kanser tanısı almış hastanın dosyası retrospektif olarak incelendi. Çalışmaya 18 yaşından büyük, tanı anında metastatik hastalığa sahip veya takipleri boyunca metastaz gelişen ve RAS mutasyonu bakılmış 75 hasta dahil edildi. Rasmutant olan ve olmayan hastaların tümör lokalizasyonu, tanı anındaki metastaz yerleri, tümör belirteçleri, tümör diferansiyasyon derecesi ve genel sağkalım süreleri arasındaki farklılıklar analiz edildi. RAS mutasyonu sıklığ $\% 50.7$ olarak saptandı. Klinik ve patolojik özellikler açısından bakıldığında RAS mutant ve wild gruplar arasında istatistiksel anlamı farklılık saptamadık. RAS mutasyon durumuna göre genel sağkalım süreleri incelendiğinde, RAS wild tip olan hastaların 2 yıllık genel sağkalımı\% 59 iken, RAS mutant hastalarımızın 2 yıllık genel sağkalımı \%27.8 idi ve bu fark istatiksel olarak anlamlıydı $(\mathrm{p}=0.004)$. Ancak, RAS wild hastaların ilk hat tedavisinde bevacizumab veya cetuksimab/panitumumab alan hastaların ortalama sağkalımları arasında (sırasıyla \%57.1'e karş1 \% 70.7; p=0.221) istatistiksel fark saptanmadı. Bu çalışmada, metastatik kolorektal kanserli hastalarımızın RAS mutasyon durumunun daha ziyade Batılı ülkelere benzer olduğunu ve hastaların tanı anındaki klinik ve patolojik özelliklerinin RAS mutasyon durumundan bağımsız olduğunu saptadık. Ancak bu konuda yapılacak prospektif ve daha geniş katılımlı çalışmalara hala ihtiyaç duyulmaktadır.

Anahtar Kelimeler: Klinik ve patolojik özellikler. Kolorektal kanser. RAS mutasyonu.

Clinical and Pathological Properties of Patients with Metastatic Colorectal Cancer According to the RAS Mutation Status

\begin{abstract}
We aimed to compare the clinical and histopathologic features at the time of diagnosis of patients with metastatic colorectal cancer according to the RAS mutation status. In this cross-sectional study, archive records of patients with diagnosing colorectal cancer who were followed-up and treated at oncology center of an university hospital in Turkey between 01.04.2012 and 24.08.2017 was analyzed retrospectively. A totally 530 patients' archieve records were evaluated. The relationship between the RAS mutant/wild groups and primary tumor localization, location of metastases at diagnosis, tumor markers, tumor differentiation grade and overall survival rates were compared with the literatüre data. We found no statistically significant difference between RAS mutant and wild groups. When overall survival rates were compared with the RAS mutation status, the overall survival of 2 years in patients with RAS wild type was 59\% while the 2 year overall survival of RAS mutant patients was $27.8 \%$ and this difference was statistically significant $(p=0.004)$. However, there was no statistically significant difference between the median survival of patients receiving bevacizumab or cetuksimab/panitumumab in th efirst line treatment of RAS wild patients (57.1\% versus $70.7 \%$; $\mathrm{p}=0.221$, respectively). In this study, we determined that RAS mutation status of our patients with metastatic colorectal cancer is more similar to Western countries and the clinical and pathological characteristics of patients at the time of diagnosis are independent of RAS mutation status. However, there is still need broader participation and prospective trials in this subject.
\end{abstract}

Key Words: Clinical and pathological properties. Colorectal cancer. RAS mutation.

Geliş Tarihi: 08 Şubat 2019

Kabul Tarihi: 08 Nisan 2019

Dr. Murat ARAZ

Necmettin Erbakan Üniversitesi Meram Tıp Fakültesi,

İç Hastalıkları Anabilim Dalı,

Tıbbi Onkoloji Bilim Dalı,

Konya.

Tel.: 05055034059

E-posta: zaratarum@yahoo.com
Rat Sarcoma (K-RAS) geni, kolorektal karsinom (KRK) gelişimindeki genetik yolaklardan biri olan tümör baskılayıcı yolda bir proto-onkogen olarak işlev görür. Aynı zamanda ekstrasellüler mitojenik sinyallerin iletiminde rol alan, GTP bağlayabilen bir membran proteinidir $^{1}$. RAS gen mutasyonları farklı kanser tiplerinde farklı insidanslarda bulunmaktadır. En yüksek oranda pankreas kanserlerinde (\%90) olmak üzere, kolonda (\%50), akciğer adenokarsinomlarında (\%30), tiroid tümörlerinde (\%50) ve myeloid lösemilerde $(\% 30)$ bu mutasyona rastlanmaktadir ${ }^{2}$. 
Metastatik KRK'li hastalarda RAS mutasyonu saptanmamıssa (wild tip) cetuksimab ve panitumumab gibi epidermal büyüme faktörü receptör inhibisyonu yapan ilaçların (anti-EGFR) standart kemoterapiye eklenmesiyle sağkalım sürelerinin uzadığı kanıtland1ğından, tedavi planı yapılmadan önce mutlaka K-RAS ve N-RAS mutasyon analizinin yapılması önerilmektedir $^{3-5}$. Ancak, CALGB/SWOG, FİRE-3, PEAK gibi en önemli KLİNIK çalışmalar çoğunlukla RAS mutasyon durumunun tedavi tercihini belirleyecek prediktif bir belirteç olup olmadığına yoğunlaşmışlardır ${ }^{5}$. Tanı anındaki RAS mutasyon durumuna göre KRK'li hastaların klinik ve patolojik özellikleri ile ilgili literatürde sınırlı çalışma ise vardır ${ }^{6-7}$.

Biz bu çalışmada RAS gen mutasyon analizi yapılmış metastatik KRK'li hastalarda RAS mutant olan ve olmayan grupları; tümör lokalizasyonu, tanı anındaki metastaz yerleri, tümör belirteçleri ile ilişkisi, tümör diferansiyasyon derecesi ile ilişkisi ve genel sağkalım açısından karşılaştırmak istedik.

\section{Gereç ve Yöntem}

Bu kesitsel çalışmada, 01.04.2012-01.01.2017 tarihleri arasında Afyon Kocatepe Üniversitesi Tıp Fakültesi Hastanesi Tıbbi Onkoloji Bölümünde takipli tüm KRK'li hastaların arşiv dosyaları retrospektif olarak incelendi.

Hastaların çalışmaya dahil edilme kriterleri;18 yaşından büyük, tanı anında metastatik olan veya takipleri boyunca metastaz gelişen hastalarda RAS mutasyonu bakılmış olması olarak belirlendi. RAS mutasyonu bakılmamış, metastatik olmayan ve takip verileri dosyada kayıtlı olmayan hastalar çalışmaya dahil edilmedi.

Toplam 530 KRK tanısı almış olan hasta dosyası tarandı. Tanı anında veya takipleri sırasında metastaz saptanmayan 375 hasta ve metastatik olduğu halde RAS mutasyon analizi yapılmamış olan 80 hasta çalışmaya dahil edilmedi. Geriye kalan toplam 75 hasta çalışmaya dahil edildi. Bu hastaların RAS mutasyon sonucu, primer tümör histolojisi ve lokalizasyonu, diferansiyasyon derecesi, tanı anındaki metastaz yerleri, tümör belirteçlerinin kan seviyeleri ve genel sağkalım süreleri kaydedildi.

\section{İstatistiksel Analiz}

İstatistiksel değerlendirme için SPSS 22.0 paket programı kullanıldı. Niteliksel veriler \% ve sıklık olarak belirtildi. Kategorik verilerin karşılaştırılmasında Kikare testi kullanıldı. Devamlı değişkenlerin normal dağılıma uygunluğu Kolmogorov-Smirnov ve Shapiro-Wilk testi ile kontrol edildi. Normal dağılım gösteren değişkenler Student t-testi ile, normal dağılım göstermeyen değişkenler Mann Whitney-U testi ile karşılaştırıldı. Genel sağkalım son kontrol veya eksi- tus tarihinden metastatik hastalık tanı tarihi çıkarılarak bulundu. Sağkalım analizi Kaplan-Meier yöntemi kullanılarak hesaplandı. Sağkalım üzerine etkili olabilecek değişkenler log-rank testi ile analiz edildi. Çalışmadaki tüm $p$ değerleri çift yönlü olup $p<0,05$ bulunan değerler istatistiksel olarak anlamlı şekilde ifade edildi.

$\mathrm{Bu}$ İç Hastalıkları Uzmanlık Tezi'nin yapılabilmesi için Afyon Kocatepe Üniversitesi Tıp Fakültesi Klinik Araştırmalar Etik Kurulu'nun 04.08.2017 tarih ve 2017/8-210 karar numarası ile izin alınmıştır. Bu çalışma Helsinki Bildirgesi prensiplerine ve iyi klinik uygulamalara uygun olarak yapılmıştır.

\section{Bulgular}

Metastatik, RAS mutasyonu bakılmış 75 KRK'li hastanın verileri analiz edildi. Hastaların ortalama takip süreleri 24 ay idi. RAS bakılan hastaların \%50.7'sinde K-RAS mutant görüldü. Hastaların sadece $\% 32$ 'sinde (24 hasta) N-RAS ve \%40'1nda (30 hasta) B-RAF mutasyonu çalışılmıştı. Ancak sadece bir hastada NRAS mutant $(\% 1,3)$ ve B-RAF mutant $(\% 1,3)$ saptandığı için değerlendirme yapılırken N-RAS ve B-RAF mutasyonu göz önüne alınmadi. $\mathrm{Bu}$ nedenle RAS mutant ifadesi K-RAS mutant olanları tanımlamak için kullanıldı. Mutasyon durumu Tablo I'de özetlenmiştir.

Tablo I. RAS ve B-RAF mutasyon durumları

\begin{tabular}{|lccc|}
\hline \multicolumn{1}{|c}{ Parametre } & $\begin{array}{c}\text { Wild tip } \\
\text { n-(\%) }\end{array}$ & $\begin{array}{c}\text { Mutant } \\
\text { n-(\%) }\end{array}$ & $\begin{array}{c}\text { Bilinmiyor } \\
\text { n-(\%) }\end{array}$ \\
K-RAS & $37-(49.3)$ & $38-(50.7)$ & $0-0$ \\
N-RAS & $23-(30.7)$ & $1-(1.3)$ & $51-(68)$ \\
B-RAF & $29-(38.7)$ & $1-(1.3)$ & $45-(60)$ \\
\hline
\end{tabular}

RAS wild tip hastalarda ortalama yaş 59 iken, mutant grupta 63 idi. Hastalarımızın RAS mutasyon durumuna göre cinsiyet, yaş, sigara kullanımı ve performans skorları incelendiğinde, wild ve mutant grupların birbirine benzer oldukları görüldü. Hastaların demografik özellikleri Tablo II'de özetlenmiştir.

Tümörün metastaz yaptığı bölgelere baktığımızda RAS wild grubun \%67'sinde (31 hasta) karaciğere, \% 9'unda (4 hasta) akciğere, \% 9'unda (4 hasta) peritona, \% 7'sinde (3 hasta) batın içi lenf noduna ve \% 4'ünde overe ( 2 hasta) metastaz yaptığı ve \% 4'ünde (2 hasta) lokal nüks olduğu saptand1. RAS mutant grupta ise wild gruba benzer şekilde metastaz oranı en yüksek organ \% 60 oranında (32 hasta) karaciğerdi. \%18'inde (10 hasta) akciğere, \%10'unda (5 hasta) batın içi lenf noduna, \%8'inde ( 4 hasta) peritona metastaz yaptığı ve \%4'ünde (2 hasta) lokal nüks saptand1. Hastaların çoğunluğunun tümör gradı belirtilmemişti. İki grup içinde de primertömürün en sık lokalize 


\section{Kolorektal Kanserde RAS Mutasyonu}

olduğu bölge rektum idi. İki grup arasında RAS mutasyon durumuna göre tümörün gradı, primertömürün yerleşim yeri ve metastaz bölgeleri açısından istatistiki anlamlı farklılık saptanmadı. (Tablo III)

Tablo II. RAS Mutasyon Durumuna Göre Hastaların Demografik Özellikleri

\begin{tabular}{|l|c|c|c|}
\hline \multicolumn{1}{|c|}{ Parametre } & $\begin{array}{c}\text { Ras Wild } \\
\mathrm{n}-(\%)\end{array}$ & $\begin{array}{c}\text { Ras Mutant } \\
\mathrm{n}-(\%)\end{array}$ & $\mathbf{p}$ \\
\hline Cinsiyet & & & \\
Erkek & $21-(56.8)$ & $17-(44.7)$ & 0.359 \\
Kadın & $16-(43.2)$ & $21-(55.3)$ & \\
\hline Yaş (medyan, min-max) & $59,23-83$ & $63.5,32-82$ & 0.259 \\
\hline ECOG* & & & \\
$\mathbf{0}$ & $3-(8.1)$ & $3-(7.9)$ & \\
$\mathbf{1}$ & $9-(24.3)$ & $6-(15.8)$ & \\
$\mathbf{2}$ & $1-(2.7)$ & $2-(5.3)$ & 0.586 \\
$\mathbf{3}$ & $1-(2.7)$ & $3-(7.9)$ & \\
Bilinmiyor & $23-(62.2)$ & $24-(63.1)$ & \\
\hline Sigara & & & \\
Var & $18-(48.6)$ & $22-(57.9)$ & \\
Yok & $16-(43.2)$ & $13-(34.2)$ & 0.469 \\
Bilinmiyor & $3-(8.1)$ & $3-(7.9)$ & \\
\hline
\end{tabular}

*ECOG: EasternCooperativeOncologyGroup

Tablo III. RAS Mutasyon Durumuna Göre Hastaların Histopatolojik ve Klinik Özellikleri

\begin{tabular}{|l|c|c|c|}
\hline \multicolumn{1}{|c|}{ Parametre } & $\begin{array}{c}\text { Ras Wild } \\
\mathrm{n}-(\%)\end{array}$ & $\begin{array}{c}\text { Ras Mutant } \\
\mathrm{n}-(\%)\end{array}$ & $\mathrm{p}$ \\
\hline Grade & & & \\
Grade 1 & $5-(13.5)$ & $4-(10.5)$ & \\
Grade 2 & $13-(35.2)$ & $11-(29)$ & 0.852 \\
Grade 3 & $3-(8.1)$ & $4-(10.5)$ & \\
Bilinmeyen & $16-(43.2)$ & $19-(50)$ & \\
\hline Lokalizasyon & & & \\
Sağ kolon & $5-(13.6)$ & $3-(7.8)$ & \\
Transvers kolon & $2-(5.4)$ & $2-(5.2)$ & \\
Sol kolon & $4-(10.8)$ & $4-(10.5)$ & 0.903 \\
Sigmoid & $12-(32.4)$ & $12-(31.5)$ & \\
Rektum & $14-(37.8)$ & $15-(39.89$ & \\
Çekum & $0-(0)$ & $2-(5.2)$ & \\
\hline Metastaz Yeri & & & \\
Karaciğer & $31-(67)$ & $32-(60)$ & 1 \\
Akciğer & $4-(9)$ & $10-(18)$ & 0.137 \\
Batın lenf nodu & $3-(7)$ & $5-(10)$ & 0.711 \\
Periton & $4-(9)$ & $4-(8)$ & 1 \\
Lokal nüks & $2-(4)$ & $2-(4)$ & 0.615 \\
Over & $2-(4)$ & $0-(0)$ & 0.240 \\
& & & \\
\hline
\end{tabular}

Hastalarımızın tanı anındaki CEA ve CA 19-9 düzeyleri RAS mutasyon durumuna göre bakıldığında, RAS mutantlarda RAS wild tip olanlara göre sayısal olarak ortalama kan tümör belirteçleri seviyesi daha yüksek olsa da tanı anındaki CEA ve CA 19-9 düzeyleri ara- sında (CEA için 25'e karş1 19, p=0.646; CA 19.9 için 81 'e karş1 16, $\mathrm{p}=0.074$; sırası ile); istatiksel anlamlı fark saptanmadi.

Birinci hat tedavide anjiogenesis inhibisyonu yaparak etki gösteren bevacizumab ile kombine kemoterapi alan 41 hastanın 39'u sol kolon, 2'si sağ kolona yerleşim gösterirken; epidermal büyüme faktör reseptörünü inhibe ederek etki gösteren cetuksimab veya panitumumab ile kombine kemoterapi alan 18 hastanın 13'ü sol kolon, 3'ü sağ kolon ve 2'si transvers kolona yerleşim gösteriyordu. RAS wild tip olup birinci hat tedavide bevacizumab ile kombine kemoterapi alan 14 hastanın hepsinde primer tümör sol kolona lokalizasyon gösterirken, cetuksimab veya panitumumab ile kombine kemoterapi alan 17 hastada, primer tümör 13'ünde sol kolona, 2'sinde sağ kolona ve 1'inde ise transvers kolona lokalizasyon gösteriyordu.

RAS mutasyon durumuna göre genel sağkalım süreleri incelendiğinde, RAS wild tip olan hastaların 2 yıllık genel sağkalımı \%59 iken, RAS mutant hastalarımızın 2 yıllık genel sağkalımı\%27.8 idi ve bu fark istatiksel olarak anlamlıydı $(\mathrm{p}=0.004)$. (Şekil 1) İlk hat kemoterapi ile kombine bevacizumab veya cetuksimab/panitumumab alan tüm hastalar genel sağkalım açısından karşılaştırıldığında ise; cetuksimab/panitumumab tedavisi alan hasta grubunda 2 yıllık genel sağkalım\%73.3 iken, bevacizumab alan grupta ise 2 yıllık genel sağkalım \% 42 olarak saptan$\mathrm{d}_{1}(\mathrm{p}=0.009)$. (Şekil 2)

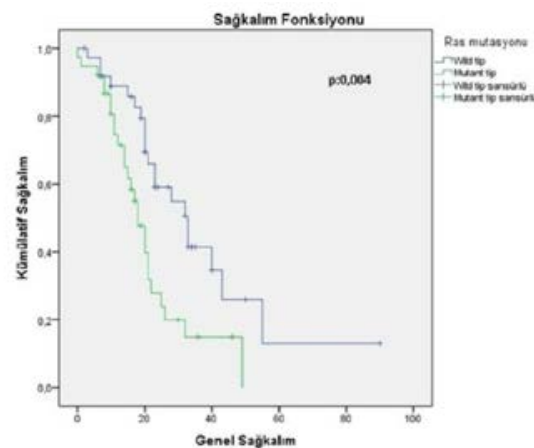

Şekil 1:

RAS mutant ve wild hastaların sağkalım grafiği

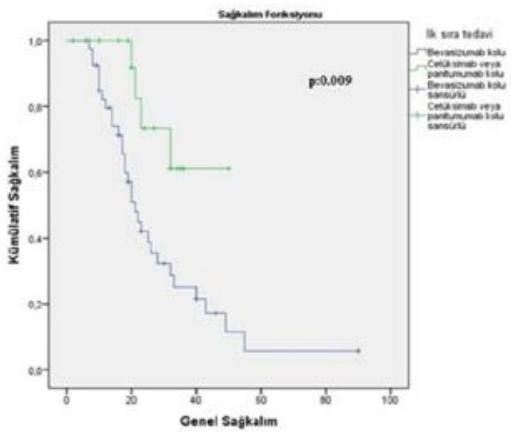

Şekil 2:

Illk hat tedaviye göre hastaların sağkalımlarının karşılaştırılması 
RAS wild tip ve ilk sıra tedavi bevacizumab ile kombine kemoterapi alan hastaların 2 yıllık genel sağkal1$\mathrm{m} 1 \% 57.1$ iken, cetuximab/panitumumab bazlı tedavi alan hastalarda 2 yıllık genel sağkalım ise \%70.7 olarak hesaplandı. Medyan genel sağkalım bevacizumab kolunda 21 ay iken cetuksimab/panitumumab kolunda ise 25.5 ay olarak saptand, ancak bu fark istatiksel farklılığa ulaşamadı. $(\mathrm{p}=0.221)$. (Şekil 3)

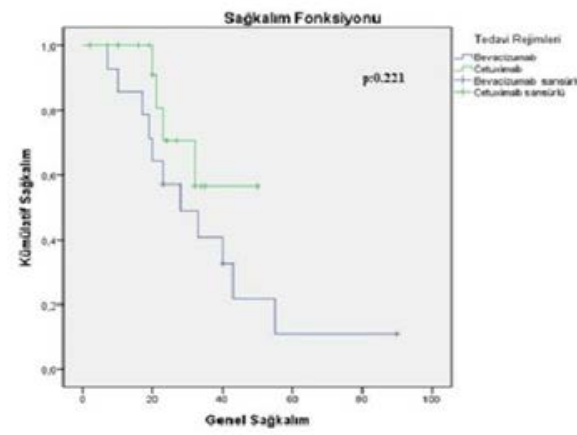

Şekil 3:

RAS wild tip grupta ilk hat tedaviye göre hastaların sağkalımlarının karşılaştırılması

Raswild ve primer tümör lokalizasyonu sol kolon olan hastaların aldıkları tedaviye göre 2 yıllık sağkalım süreleri değerlendirildiğinde; bevacizumab kolunda 2 yıllık genel sağkalım\%57.1iken, cetuksimab/panitumumab kolunda ise bu oran \%88.9 olarak saptandı ancak iki grup arasında istatiksel fark bulun$\operatorname{mad}_{1}(\mathrm{p}=0.08)$. (Şekil 4)

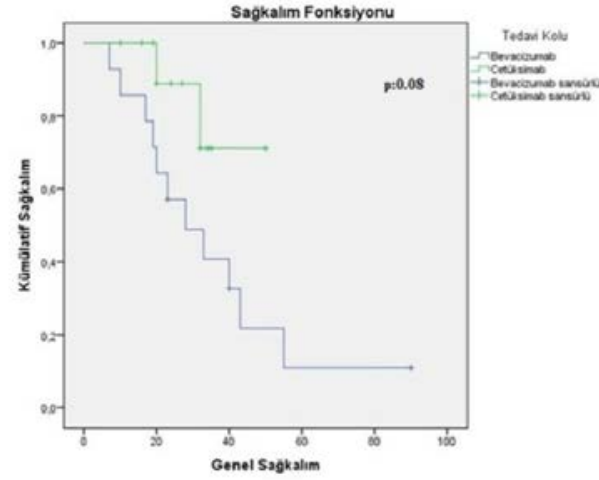

Şekil 4:

RAS wild tip ve primer tümör lokalizasyonu sol kolon olan hastaların ilk hat tedaviye göre sağkalımlarının karşılaştırılması

RAS wild tip ve primer tümörü sağ kolon yerleşimli olan hastalarda birinci hat tedavide cetuksimab/panitumumab alanlarda ortalama genel sağkalım 10 ay (min:7, max:23) iken; RAS wild ve sol kolon yerleşimli primer tümörü olan hastalarda birinci sıra tedavide cetuksimab/panitumumab alanlarda medyan genel sağkalım25.5 ay (min: 10, max: 50) olarak saptandı. RAS wild ve sağ kolon yerleşimli hastalarımızın hiçbiri ilk hat tedavide bevacizumab kullanmadığı için değerlendirme yapılamadı.

\section{Tartışma}

$\mathrm{Bu}$ kesitsel çalışmada, metastatik KRK 'li hastaların yaklaşık yarısında RAS mutasyonu pozitif olarak saptadık. Klinik ve patolojik özellikler açısından bakıldığında RAS mutant ve wild gruplar arasında istatistiksel anlamı farklılık saptamadık. RAS wild tip olup ilk hat tedavide bevacizumab veya cetuksimab/panitumumab ile kombine kemoterapi alan hastalarda genel sağkalım açısından istatiksel anlamlı fark saptanmadi.

Literatüre bakıldığında, RAS mutasyon sıklığı Batı toplumlarında \%55 oranında iken, Asyalı toplumlarda yapılan çalışmalarda bu oran daha düşük düzeyde saptanmıştır ${ }^{6}$. RAS mutasyon sıklığı Saupaulo’da\%49.2 ve Texas'da \% 51.3 ${ }^{8-9}$, Endonezya'da \% $41^{6}$, Singapur'da \% 33.3, Tahran'da \%33.6 ve Japonya'da \%37.8 oranında belirlenmiştir ${ }^{10-12}$. Bizim çalışmamızdaki RAS mutasyon oranı (\%50.7) daha ziyade Batı'lı toplumundaki sıklık ile uyumlu olarak saptandi.

Morris ve arkadaşlarının Texas'da yapmış oldukları çalışmada $^{9}$, RAS mutasyonu pozitifliğinin müsinöz histoloji ile daha sık görüldüğü bildirilmiş olsa da ( $\mathrm{P}$ $<0.001$ ), bunun aksine, Koochak ve arkadaşlarının ${ }^{12}$ Tahran'da yapmış oldukları çalışmada RAS mutasyonlarına non-musinöz tümörlerde $(\mathrm{P}=0.0001)$ daha sık rastlanılmıştır ${ }^{12}$. Bizim çalışmamızda ise tümör histolojik alt tipine bakılan hasta sayısı kısıtlı olduğu için istatistiksel değerlendirme yapılamadı. RAS mutasyon durumuna göre tömür diferansiyasyonu iki grupta da literatürdeki diğer çalışmalar ile uyumlu olarak çoğunlukla orta ve iyi derecede diferansiye olarak saptandi ${ }^{10,12}$.

Çalışmamızda, iki grupta da en sık metastaz yeri karaciğer olarak izlenmekle birlikte, akciğer metastazı RAS mutant hastalarda RAS wild hastalara göre daha yüksek oranda izlendi, ancak bu fark istatistiksel anlamlılığa ulaşamadı $(p=0.137)$. Sao Paulo ve Texas'da metastatik KRK'li hastalar ile yapılan çalışmalarda, bizim çalışmamızla uyumlu olarak RAS mutant olan ve olmayan iki grupta da en sik metastaz yeri karaciğer olarak bildirilmiş ve iki grup arasında istatistiksel fark saptanmamıştır ${ }^{8-9}$. Bizim çalışmamızdan ve literatürdeki diğer sonuçlardan farklı olarak, Kawazoe ve arkadaşlarının Japonya'da yaptıkları çalışmada RAS mutasyonundan bağımsız olarak kolorektal kanserin karaciğer metastazı ile hemen hemen aynı oranda lenf nodlarına da metastaz yaptığ 1 bildirilmiştir ${ }^{11}$.

Bizim çalışmamızda, RAS wild olan hastaların 2 yıllık genel sağkalım oranı ve medyan genel sağkalımı mutant olanlara göre istatistiksel anlamlı olarak daha uzun (p: 0.008) bulundu. Sao Paulo, Texas ve Japon- 


\section{Kolorektal Kanserde RAS Mutasyonu}

ya'da yapılan çalışmalarda medyan genel sağ kalım sonuçları bizim sonuçlar ile benzerdi ${ }^{8-9,11}$. Sadece Sao Paulo2daki çalışmadaki sonuçlar istatistiksel anlaml1lığa $(p=0.407)$ ulaşamamıştı ${ }^{3}$. Akman ve arkadaşlarının retrospektif çalışmasında ise, bizim çalışmamızdan ve literatürden farklı olarak RAS mutant hastaların medyan genel sağkalımı RAS wild olanlara göre daha uzun saptanmıştı, fakat bu fark istatistiksel olarak anlam ifade etmemekteydi ${ }^{13}$.

RAS wild olan ve ilk sira tedavi olarak cetuksimab/panitumumab alan hastalarda 2 yıllık genel sağkalım ve medyan genel sağkalım bevacizumab tedavisi alanlara göre sayısal olarak daha uzun izlenmesine rağmen istatistiksel fark saptamadik $(p=0.221)$. En önemli çalışmalardan biri olan FIRE-3 çalışmasında ${ }^{14}$, aynı özellikleri taşıyan hasta popülasyonunda cetuksimab alan kolda medyan genel sağkalım daha uzun olup istatistiksel fark saptanmıştı (33.1 vs25.6 ay, p= 0.011), ancak diğer önemli ikinci çalışma olan CALBG çalışmasında ${ }^{15}$, iki grubun medyan genel sağkalımları birbirine çok yakın olup istatistiksel olarak fark saptanmamıştı ( 30 vs 29 ay, $\mathrm{p}=0.08$ ). Tümör küçültme oranları ve progresyonsuz sağkalımları benzer olan bu iki çalışmada genel sağkalım arasındaki bu fark izah edilememişti.

Çalışmamızda, RAS wild tip ve birinci hat tedavide cetuksimab/panitumumab alan hastaların primer tümör lokalizasyonuna göre medyan genel sağkalım karşılaştırıldığında, sol kolon yerleşimli tümörü olan hastalarda medyan genel sağkalım sağ kolon yerleşimli hastalara göre daha uzun (25.5 vs 10 ay) saptand1. Benzer şekilde, CRYSTAL çalışması (28.7 vs18.5 ay, $\mathrm{p}=0.003$ ) ve FIRE-3 (38.3 vs $18.3 \mathrm{p}=<0.001)$ çalışmasının retrospektif analizinde de, primer tümörün sol kolona yerleşimli olduğu hastalarda medyan genel sağkalım, çalışmamızla benzer şekilde istatistiksel anlamlı olarak daha uzun saptanmışt1 ${ }^{16}$.

Ayrıca, FIRE-3 çalışmasının retrospektif analizinde RAS wild olan ve birinci sira tedavide kemoterapi ile kombine bevacizumab alan hastalarda, primer tümör yerleşimi sol kolon olanlarda medyan genel sağkalım sağ kolon yerleşimli hastalara göre istatistiksel anlamlı olarak uzun (28 vs 23 ay $\mathrm{p}=<0.04)$ saptanmışt1 ${ }^{16}$. Bizim çalışmamızda ise, RAS wild ve bevacizumab alan hastaların hepsi primer tümör sol kolon yerleşimli olduğu için karşılaştırma yapılamamamıştır.

Bizim çalışmamızda, RAS wild tip ve sol kolon yerleşimli tümörü olan hastalarımızın, birinci hat tedavi rejimine göre 2 yıllık genel sağkalım oranları karşılaştırıldığında; cetuksimab/panitumumab alan hastalarda bevacizumab alanlara göre genel sağkalım oranı sayısal olarak daha yüksek olmasına istatistiksel fark (\%88.9vs \%57.1, p=0.08) saptanmadi. Burada istatiksel fark saptanmamasının nedeni hasta sayımızın azl1ğına bağlanabilir. FIRE-3 çalışmasının retrospektif analizinde ise, çalışmamızdan farklı olarak cetuksimab alan kolda medyan genel sağkalım istatistiksel anlaml olarak (38.3 vs 28 ay, $\mathrm{p}=0.002$ ) belirgin şekilde daha uzundu $^{16}$.

Sonuç olarak, retrospektif tasarımı ve hasta sayısının azlığı çalışmamızın sonuçlarını yorumlarken kısıtlılıklar oluştursa da, metastatik KRK'li hastalarda RAS mutasyon durumunun daha ziyade Batılı ülkelere benzer olduğunu ve hastaların tanı anındaki klinik ve patolojik özelliklerinin RAS mutasyon durumundan bağımsız olduğunu saptadık. Ancak bu konuda yapılacak prospektif ve daha geniş katılımlı çalışmalara hala ihtiyaç duyulmaktadır.

\section{Teşekkür}

Çalışmanın istatistiki analizlerini yapan Afyon Sağlık Bilimleri Üniversitesi İç Hastalıkları A.B.D ve Nefroloji B.D.'dan Uzm. Dr. Sinan Kazan'a teşekkür ederiz.

\section{Kaynaklar}

1. Zeng M, Kikuchi H, Pino MS, Chung DC. Hypoxia activates the K-ras proto-oncogene to stimulate angiogenesis and inhibit apoptosis in colon cancer cells. PLoS One 2010;5(6). e10966.

2. Jiang $\mathrm{Y}$, Mackley $\mathrm{H}$, Cheng $\mathrm{H}$, Ajani JA. Use of K-Ras as a predictive biomarker for selecting anti-EGF receptor/pathway treatment. Biomark Med 2010 Aug; 4(4): 535-41.

3. Kim D, Hong YS, Kim JE, et al. Use of a high-throughput genotyping platform (OncoMap) for RAS mutation alanalysis to predict cetuximab efficacy in patients with metastatic colorectal cancer. Cancer ResTreat 2017;49(1):37-43.

4. Douillard J-Y, Oliner KS, Siena S, et al. PanitumumabFOLFOX4 treatment and RAS mutations in colorectal cancer. N Engl J Med 2013;369(11):1023-1034.

5. Heinemann V, Rivera F, O’Neil BH, et al. A study-level metaanalysis of efficacy data from head-to-head first-line trials of epidermal growth factor receptor inhibitors versus bevacizumab in patients with RAS wild-type metastatic colorectal cancer. Eur J Cancer 2016;67:11-20.

6. Levi M, Prayogi G, Sastranagara F, et al. ClinicopathologicalAssociations of K-RAS and N-RAS Mutations in Indonesian Colorectal Cancer Cohort. J Gastrointest Cancer 2017;1-8.

7. Zekri J, Karim SM, Al-Shehri A, Mahrous M, Darwish T, El Taani H. Frequency and clinical impact of KRAS mutations in patients with colorectal cancer from the middle east. J Anal Oncol 2016;5(2):67-74.

8. Ribeiro KB, Feres O, Ribeiro da Rocha JJ, et al.Clinicalpathological correlation of KRAS mutation status in metastatic colorectal adenocarcinoma. World J Oncol 2013;4(4-5):179187.

9. Morris VK, Lucas FAS, Overman MJ, et al. Clinicopathologic characteristics and gene expression analyses of non-KRAS 12/13, RAS-mutated metastatic colorectal cancer. Ann Oncol 2014;25(10):2008-2014.

10. Phua LC, Ng HW, Yeo AHL, et al. Prevalence of KRAS, BRAF, PI3K and EGFR mutations among Asian patients with metastatic colorectal cancer. Oncol Lett 2015;10(4):2519-2526.

11. Kawazoe A, Shitara K, Fukuoka S, et al. A retrospective observational study of clinicopathological features of KRAS, NRAS, BRAF and PIK3CA mutations in Japanese patients with metastatic colorectal cancer. BioMed Cent Cancer 2015;15:258. 


\section{Sezen, ark.}

12. Koochak A, Rakhshani N, Karbalaie Niya MH, et al. Mutation Analysis of KRAS and BRAF Genes in Metastatic Colorectal Cancer: a First Large Scale Study from Iran. Asian Pac J Cancer Prev 2016;17(2):603-608.

13. Akman T, Oztop I, Baskin Y, et al. The association of clinicopathological features and survival in colorectal cancer patients with kras mutation status. J Cancer Res Ther 2016;12(1):96102.

14. Heinemann V, Weikersthal LF Von, Decker T, et al. FOLFIRI plus cetuximab versus FOLFIRI plus bevacizumab as first-line treatment for patients with metastatic colorectal cancer (FIRE3): A randomised, open-label, phase 3 trial. LancetOncol 2014;15(10):1065-1075.
15. Venook AP, Niedzwiecki D, Lenz H-J, et al. Metastatic adenocarcinoma of the colon or re CALGB/SWOG 80405: Phase III trial of irinotecan/5-FU/leucovorin (FOLFIRI) oroxaliplatin/5FU/leucovorin (mFOLFOX6) withbevacizumab (BV) orcetuximab (CET) for patients (pts) with KRAS wild-type (wt) untreated. J Clin Oncol 2014:20; 32(15_suppl): LBA3-LBA3.

16. Tejpar S, Stintzing S, Ciardiello F, et al. Prognostic and predictive relevance of primary tumor location in patients with ras wild-type metastatic colorectal cancer retrospective analyses of the CRYSTAL and FIRE-3 trials. In: JAMA Oncology 2017;194-201. 